\title{
ARTÍCULOS
}

\section{La Tradición Budista Mādhyamika y su Concepción del}

\section{Lenguaje}

\section{The Mādhyamika Buddhist Tradition and its Conception of Language}

\author{
María Fernanda Mayorga Sabogal \\ Universidad Pedagógica Nacional de Bogotá, Colombia \\ mafe9863@gmail.com
}

\section{RESUMEN:}

El propósito de este texto es adentrarnos en el conocimiento de la tradición budista mādhyamika. Así, nuestra pretensión es exponer los principios más fundamentales de esta tradición, no solo con el propósito de conocer las bases de la misma, sino también con miras a realizar un análisis sobre la concepción del lenguaje que tiene esta escuela budista. Cabe aclarar que este texto está sustentado, principalmente, en el libro La palabra frente al vacío del filósofo español Juan Arnau, ya que este autor, al ser especialista en filosofía oriental (Arnau, 2003), logra explicar con claridad y con profundidad los temas sobre los que se basa nuestro estudio.

Palabras Clave: Tradición budista, Filosofía del lenguaje, Filosofía de la religión.

\section{ABSTRAC:}

The purpose of this text is to enter into the knowledge of the Buddhist mādhyamika tradition. Thus, our intention is to expose the most fundamental 
presentan, generando, a partir de dichas interpretaciones, discursos que primero nos permitan adaptarnos al mundo convencional; segundo, nos permitan generar nuevos significados que deleiten el pensamiento; $y$, tercero, que nos concedan la libertad del sufrimiento que trae el considerar la vacuidad de todo lo existente. En suma, veremos que el lenguaje se desplaza de la verdad conceptual a lo metafórico, a lo retórico y a lo discursivo, pues el lenguaje, más que demostrar la verdad, juega a crear representaciones ilusorias.

\section{La tradición mādhyamika como la tradición del camino medio}

Inicialmente, es preciso decir que la escuela mādhyamika es una tradición del budismo mahāyāna popularizada por Nāgārjuna (2004). Es decir, Nāgārjuna se reconoce como el filósofo budista más influyente en la fundación de esta escuela. Fundamentalmente esta tradición es considerada como el camino medio, o la vía media. Los mādhyamikas siguen la vía media en razón de que no consideran ni la existencia ni la no existencia, es decir, ellos no se comprometen ni con la afirmación que sostiene que 'todo existe', ni tampoco con la que dice que 'nada existe'. En comparación con otros posicionamientos filosóficos, esta tradición no se inclina radicalmente ni por una ascética extrema como la de los jainaistas ${ }^{1}$, ni por un hedonismo radical como el del epicureísmo².

$\mathrm{Al}$ respecto, Juan Arnau comenta que el mādhyamika es el camino medio que rechaza los extremos de un excesivo rigor ascético y de una vida demasiado

\footnotetext{
${ }_{1}^{1}$ Los jainaistas ejercitan un disciplinado ascetismo a través de prácticas como el ayuno y la mortificación del propio cuerpo. A través de estas actividades esperan destruir la ley kármica y evitar posteriores reencarnaciones.

2 El epicureísmo es una doctrina filosófica cuyas principales ideas consisten en defender que el placer constituye el bien supremo y la meta a alcanzar.
} 


\section{ARTÍCULOS}

fácil y secular. De manera tal que es un camino que discurre entre dos extremos: entre la búsqueda desenfrenada del placer y la práctica obsesiva del ascetismo, entre la idea realista ${ }^{3}$ de que todo existe y la idea nihilista ${ }^{4}$ de que nada es (Arnau, 2005, pp. 60-61). En ese sentido, la tradición del camino medio tiene como eje principal una posición antiesencialista, en el sentido en que no establece un fundamento esencial. Así, para esta tradición lo esencial o lo verdadero no es ni el todo ni la nada; no se inclina hacia la eternidad (sasvata) ni tampoco hacia la aniquilación (uccheda). Ahora bien, a continuación, explicaremos cuál es el sentido de la vacuidad y la contingencia con el propósito de sustentar el por qué esta tradición no se inclina hacia ninguno de los dos extremos mencionados.

\section{Sobre la vacuidad y la contingencia}

La palabra en sánscrito sūnyāta, que traducida al español significa vacuidad, es una palabra vieja que toma un lugar central en el pensamiento mādhyamika. Cabe aclarar que la vacuidad es un concepto muy difícil de explicar y de entender, lo cual se debe a la contradicción aparente que conlleva. De hecho, se dice que durante más de un milenio se produjeron diferentes interpretaciones y hermenéuticas sobre dicho concepto. Es por ello que este trabajo resulta siendo un pequeño abrebocas de lo que es la tradición mādhyamika, ya que ella y su concepción de la vacuidad es un tema en demasía profundo, complejo y extenso.

La etimología de la palabra vacuidad (sūnyāta) está compuesta del adjetivo shuniá (vacío), y el sufijo tuá (cualidad), y significa 'cualidad de lo vacío'. La vacuidad

\footnotetext{
${ }^{3}$ El realismo es la forma de ver los hechos o las cosas tal como son en realidad.

${ }^{4}$ El nihilismo en una corriente filosófica que sostiene la imposibilidad del conocimiento y que niega los principios morales y éticos.
} 
